
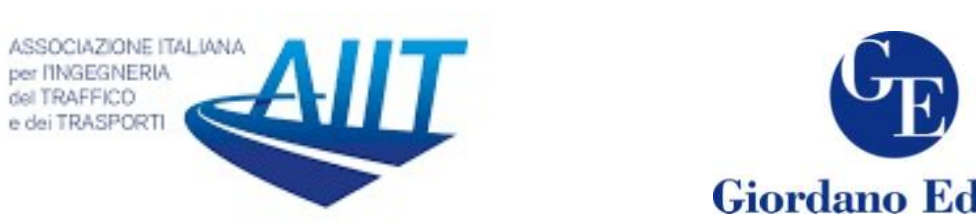

Giordano Editore

\title{
Effects of Inter-Vehicle Interaction on Speed and Lateral Position for Reviewing Free - Flow Condition
}

\author{
Gourab Sil $^{1^{*}}$, Avijit Maji ${ }^{2}$, Akhilesh Kumar Maurya ${ }^{3}$, Suresh Nama $^{3}$ \\ ${ }^{I}$ Dept. of Civil Engineering, Indian Institute of Technology Indore, Indore: 453552, India \\ ${ }^{2}$ Dept. of Civil Engineering, Indian Institute of Technology Bombay, Maharashtra: 400076, India \\ ${ }^{3}$ Dept. of Civil Engineering, Indian Institute of Technology Guwahati, Assam: 781039, India
}

\begin{abstract}
Speed and lateral position of free-flowing vehicles are the performance measures of roadway geometric elements. Most of the earlier studies evaluated a threshold headway based free-flow criteria at an observation station and considered the relevant vehicles for estimation of speed and lateral position. However, evaluation of free-flow at one observation station cannot guarantee the same in the entire segment, due to the possible inter-vehicle interactions prior to the observation station. It can cause inappropriate performance evaluation of the roadway geometric element. Moreover, horizontal curve is one of the critical geometric elements of four-lane highways. Hence, in this research, all the possible intervehicle interactions of passenger cars prior to a curve center of four-lane divided highways were identified and analyzed for the effect of inter-vehicle interactions on speed and lateral position. The analysis indicates that speed and lateral position are dependent on the location of inter-vehicle interactions prior to a curve center. Vehicles, which did not interact with other vehicles until the curve center, remains uninfluenced and should be considered for geometric evaluation. This finding is useful to identify the relevant free-flowing vehicles and in-turn, improve the evaluation of horizontal curve geometry.
\end{abstract}

Keywords: Speed, lateral position, horizontal curve, free-flow, geometric evaluation

\section{Introduction}

Vehicle drivers start perceiving a horizontal curve at the curve discovery segment, located about 50m to $100 \mathrm{~m}$ upstream of a curve start point (Zwahlen and Schnell 1999; Campbell et al. 2008; Sil et al. 2019a), and initiate speed adjustment for the perceived geometry (Hashim et al. 2016; Glennon et al. 1983). It reflects their expectancies to choose an appropriate speed based on their perception of the curve geometry. Earlier studies indicated that driver's error in speed selection is the primary reason for the single-vehicle crashes (Mohan et al. 2015; Maji et al. 2018; Fagnant and Kockelman 2015) and therefore, speed was considered as one of the fundamental parameters for safety evaluation. Operating speed, considered as the anticipated speed that majority of the drivers adapt based on their perception of the alignment geometry and cross-section environment, has been extensively used for safety and consistency evaluation of

\footnotetext{
* Corresponding author. Tel.: +91-9038152961

E-mail address: silgourab@gmail.com
} 
horizontal curve geometry. This speed is influenced by the alignment geometry and crosssection environment, and is generally defined as the 85th percentile of the free-flow speed distribution (AASHTO 2011). So, the safety and consistency evaluation greatly depends on the estimated operating speed, which in-turn depends on the free-flow speed data.

Since 1950s, researchers have been using spot speed data and evaluated the free-flow condition using a threshold headway condition at curve center (Taragin 1954; Lamm et al. 1995; Fitzpatrick et al. 2000; Jacob and Anjaneyulu 2012; Maji et al. 2018; Maji and Tyagi 2018). Some researchers argued on the effectiveness of spot speed data at the curve center and recommended speed profile data for safety evaluation of horizontal curves (Ottesen and Krammes 2000; Fitzpatrick and Collins 2000; Misaghi and Hassan 2005; Hashim et al. 2016). So, to assess the safety in four-lane highways, evaluation of freeflow condition only at one location (such as curve center) might not be appropriate. The subject vehicle's speed and lateral position at the curve center could change due to vehicular interactions (e.g., passing movements) prior to the observation location (Sil et al. 2019a). Figure 1 presents the time-distance diagram for the passing movement (viz. vehicular interaction) in four-lane divided highways. A fast-moving vehicle may not reduce speed but explicitly change the lane well before passing (AASTHO 2011) and could meet the threshold headway condition at the observation station (i.e., at station 2 of Figure 1). This vehicular interaction might influence driving behavior such as speed choice and lateral position (Rawson, 2015). Hence, the lateral position can be considered as a complementary measure to emphasize the effect of inter-vehicle interaction in geometric element evaluations. This study examines the influence of inter-vehicle interactions on speed and lateral position to efficiently identify the vehicles moving in true free-flow condition, and proposes a suitable free-flow evaluation condition.

Researchers used different methods to collect speed data at horizontal curves and other traffic parameters in developing countries like India. Most of these methods include global positioning system (GPS) fitted vehicles (Nama et al. 2018), radar gun (Jacob and Anjaneyulu 2012; Nama et al. 2016), video recording techniques (Boora et al. 2016; Dey et al. 2006; Sil et al. 2018a,b; Sil et al. 2019a, b, c; Maji et al. 2018; Maji and Tyagi 2018; Sil et al. 2020a, b; Memon et al. 2008), and driving simulator (Choudhari and Maji, 2017; Choudhari and Maji, 2018; Choudhari and Maji, 2019a; Choudhari and Maji, 2019b; Choudhari and Maji, 2019c). Sil and Maji (2017a) reviewed these methods and found the video recording techniques as reliable and comparable with other available methods. Further, using video recording techniques, researchers had collected lateral position data by dividing the lane width into $25 \mathrm{~cm}$ sections (Dey et al. 2006; Mohapatra and Dey 2015). The rear left wheel position of a vehicle crossing any section was recorded as that vehicle's lateral position. These data, representing the lateral position distributions, were used to study the Indian driving behavior. However, the presence of video camera and trap markings might influence the driver behavior (speed and lateral position). Studies to explain the influence of video camera and trap markings on the driver behavior (speed and lateral position) are not available for four-lane highways in India and warrants further investigations. Furthermore, all of the studies had evaluated the free-flow condition only at the observation station and did not examined the possible influence of inter-vehicle interactions prior to that station. Hence, studies to examine the effects of prior intervehicle interactions on the driver behavior (viz. speed and lateral position) at the curve center of four-lane highways are needed. Therefore, the objectives considered in this research are as follows:

(i) To investigate the effects of trap markings and video cameras on speed; 
(ii) To evaluate the effect of prior inter-vehicle interactions on speed and lateral position at the center of horizontal curves in four-lane divided highways; and

(iii) To develop a suitable free-flow evaluation condition for geometric safety and consistency evaluation of horizontal curves in four-lane divided highways.

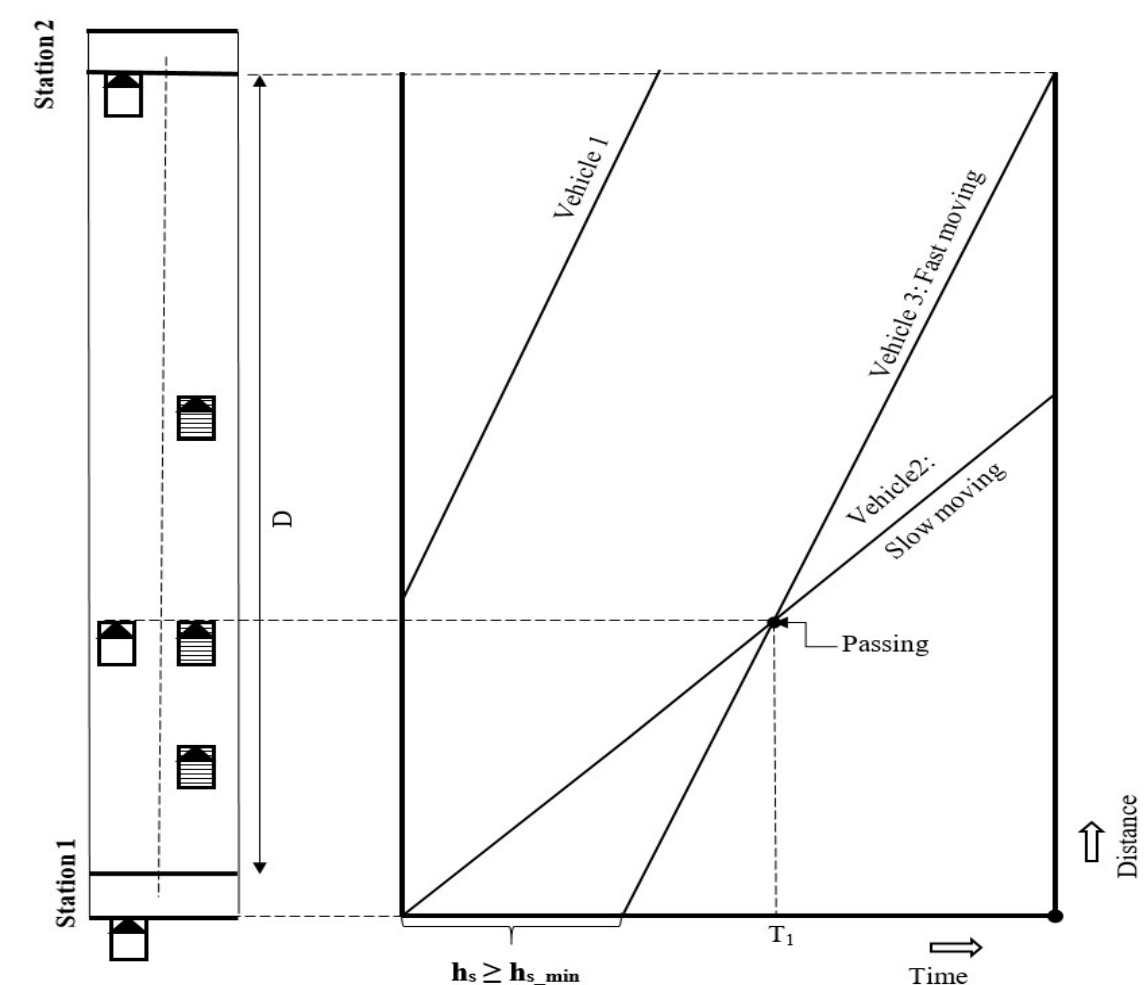

Where, $\quad T_{l}=$ Passing time of two vehicles, $D=$ Distance between consecutive station ( $m$ ) $h_{s}=$ Headway (sec), $-a=$ Deceleration, $+a=$ Acceleration

$\square=$ Fast moving vehicle, 血 = Slow moving vehicle

Figure 1: Time-distance diagram for passing movements (Sil and Maji 2017a)

\section{Study Framework}

The framework adopted to accomplish the study objectives is presented in Figure 2. It can be observed that this research starts with the selection of sites for evaluating the effect of inter-vehicle interactions on speed and lateral position at the center of horizontal curves in four-lane divided highways. Thereafter, a preliminary study to investigate the effects of trap markings and video cameras on speed was reviewed before initiating the data collection using video recording technique. The collected data was used to analyze the effect of inter-vehicle interactions on speed and lateral position.

\section{Site Selection}

The scope of this study was restricted to four-lane divided highways. Total four horizontal curves were chosen for data collection on the National Highway 3 (NH-3) connecting Thane and Nasik in the state of Maharashtra, India. Curve radius up to $400 \mathrm{~m}$ predominately influences driver behavior (Sil et al. 2019a; Lamm et al. 1990; Fitzpatrick et al. 2000). Hence, horizontal curves with radii $90 \mathrm{~m}, 165 \mathrm{~m}, 280 \mathrm{~m}$, and $360 \mathrm{~m}$, covering a range up to $400 \mathrm{~m}$, were selected for this study. All the selected sites had similar 
carriageway width of $7 \mathrm{~m}$ on either side of the median, shoulder width of $3 \mathrm{~m}$ on the far sides of the cross-section, superelevation of $2.5 \%$, gradient up to $2 \%$ and asphaltic concrete surface. These sites were selected only in the rolling terrain. The survey was conducted during daytime and in dry pavement conditions. Moreover, these sites were chosen carefully to satisfy the following conditions:

i) Avoid the presence of intersections or median openings and roadside interference to eliminate unwanted influence,

ii) Presence of uniform lane markings and guardrail,

iii) Adequate sight distance, and

iv) Availability of vantage points for installing video cameras concealed from driver's cone of vision.

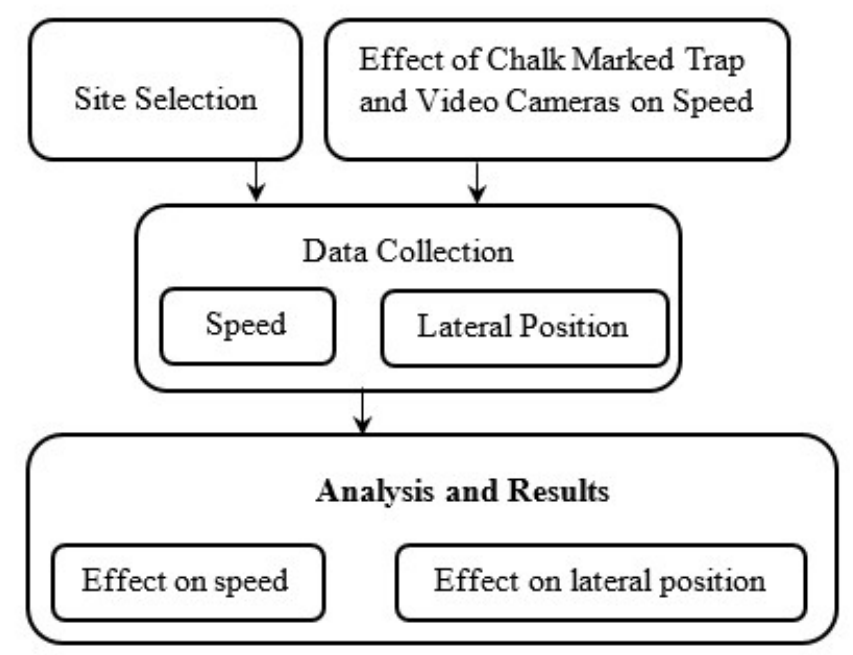

Figure 2: Framework of the study

\section{Effect of Chalk Marked Trap and Video Cameras on Speed}

To compare the speed with and without the presence of chalk-marked traps and video cameras, a preliminary study was conducted prior to the primary data collection. Test vehicles fitted with V-Box ${ }^{\circledR}$ were driven through a test section (i.e., curve center). Speed of 35 vehicles ( sample size $=35$ ) at curve center was extracted and considered as data set 1. Afterward the pavement of the same test section was chalk-marked for trap length reference and a video camera was installed at a vantage point, concealed from the driver's view. The speed estimated from the video recording of 35 random vehicles passing the trap length (sample size $=35$ ) was considered as data set 2 . Normality of both the data set was successfully verified. Mean $(\mu)$ of the two speed data sets was compared using a two sample t-test at $95 \%$ confidence interval. The obtained P-value (i.e., 0.076 $>0.05$ ) indicated that both data sets were not significantly different and belonged to the same population. The results of the two sample t-test are presented in Table 1. Moreover, similar finding reported by Tyagi (2016) supports that the effect of chalk-marked reference points and video cameras on driver's speed choice is insignificant. Earlier research works also used chalk-marked reference points along with video cameras for speed data collection (Dey et al. 2006; Maji et al. 2018; Maji and Tyagi 2018). Therefore, data collection using video camera and trap was considered suitable for the present study. 
Table 1: Two-sample t-test results

\begin{tabular}{ll}
\hline Difference & $\mu($ V-box $)-\mu($ Video $)$ \\
\hline Estimate for difference & 3.58 \\
95\% CI for difference & $(-0.40,7.56)$ \\
T-Test of difference & 0 \\
T-Value & 1.83 \\
P-Value & 0.076 \\
DF & 34 \\
\hline
\end{tabular}

\section{Data Collection and Preliminary Analysis}

Before developing the speed and lateral position data collection setup, it was essential to plan the vehicle tracking process for all the possible inter-vehicle interactions prior to the curve center. The video-based data collection methodology proposed by Sil and Maji (2017a) was adopted for vehicle tracking. As shown in Figure 3, three locations: (i) $50 \mathrm{~m}$ prior to a point of curvature $\left(\mathrm{PC}_{50}\right)$, (ii) point of curvature (PC) and (iii) curve center (CC) along a curve were considered for vehicle tracking (Figure 3). The tracking starts from $\mathrm{PC}_{50}$ and ends at $\mathrm{CC}$. The intermediate observation station $\mathrm{PC}$ was set up for continuity in surveillance of a subject vehicle for inter-vehicle interaction between $\mathrm{PC}_{50}$ and $\mathrm{CC}$.

Researchers assumed constant speed along the curve (Bassani et al. 2016; Hassan et al. 2011) and considered collecting free-flow speed data only at curve center to estimate the operating speed for the speed prediction models. Generally, vehicles interacting with other vehicles only at the curve center was not considered for the purpose. In contrary, this study considered a vehicle as interacted if it failed to satisfy the threshold headway criteria (with respect to same or adjacent lane vehicle) at the tracking locations $\mathrm{PC}_{50}, \mathrm{PC}$ and $\mathrm{CC}$ or overtook/overtaken between those tracking locations (see Figure 3). Reasonably accepted criteria of $5 \mathrm{sec}$ threshold headway (Fitzpatrick et al. 2000; Hashim et al. 2016; Gong and Stamatiadis 2008) was adopted for the purpose. So, the four cases when a vehicle did not interact at curve center (e.g., maintain headway $\geq 5 \mathrm{sec}$ at CC) were:

i) Not interacted (NI) at all three locations (NI-NI-NI);

ii) Interacted (I) at the first location only (I-NI-NI);

iii) Interacted (I) at the second location only (NI-I-NI); and

iv) Interacted (I) at first and second locations (I-I-NI)

In this study, speed and lateral position (LP) of the passenger cars were considered. Figure 4 presents a typical image of the pavement marking set-up. It is worth to note that the present study used digital video cameras of $0.04 \mathrm{sec} /$ frame accuracy. The $15 \mathrm{~m}$ trap yields a nominal error in speed estimation using video cameras of $0.04 \mathrm{sec} /$ frame accuracy (Sil and Maji 2017a,b). Hence, vehicle speed was estimated from the timestamps (obtained from the video logs) corresponding to the vehicle crossing the boundary of $15 \mathrm{~m}$ trap marked on the pavement as shown in Figure 3 and Figure 4. For the lateral position data, the carriageway was divided and marked into sections of $25 \mathrm{~cm}$ as presented in Figure 3 and Figure 4. During data extraction from video logs, the front left wheel crossing the marked section was recorded as the lateral position of the vehicle from the carriageway edge on the shoulder side. The edge of the lane marking representing the carriageway edge from the shoulder side was considered as the origin for lateral position measurement (see Figure 3 and Figure 4). 


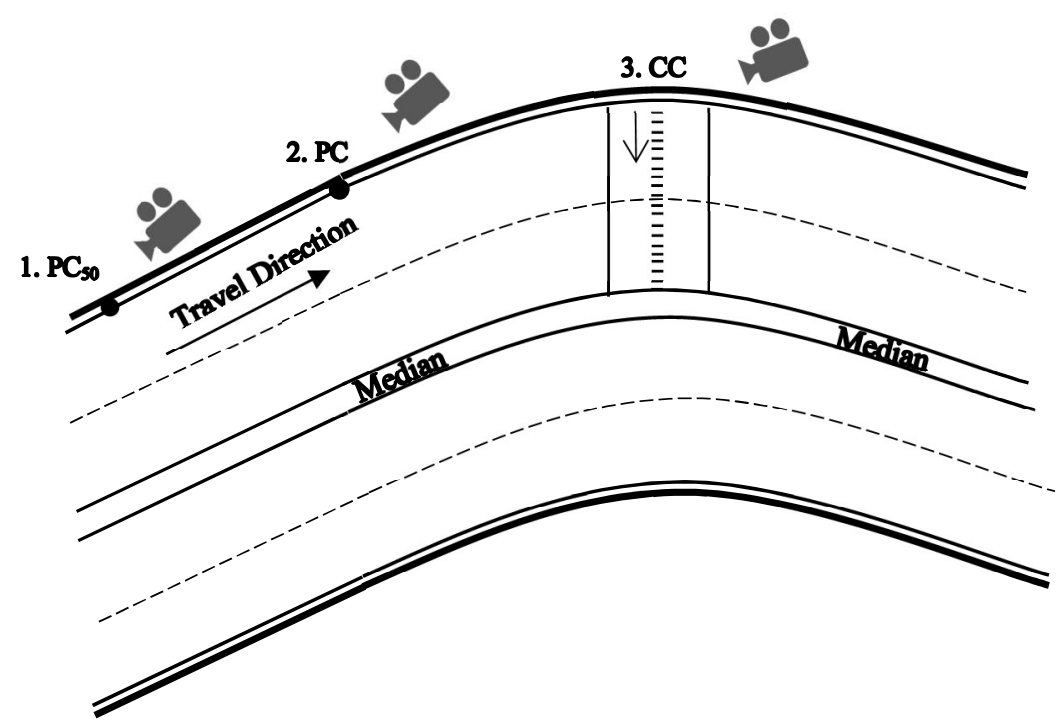

Figure 3: Schematic diagram of the vehicle tracking along a horizontal curve

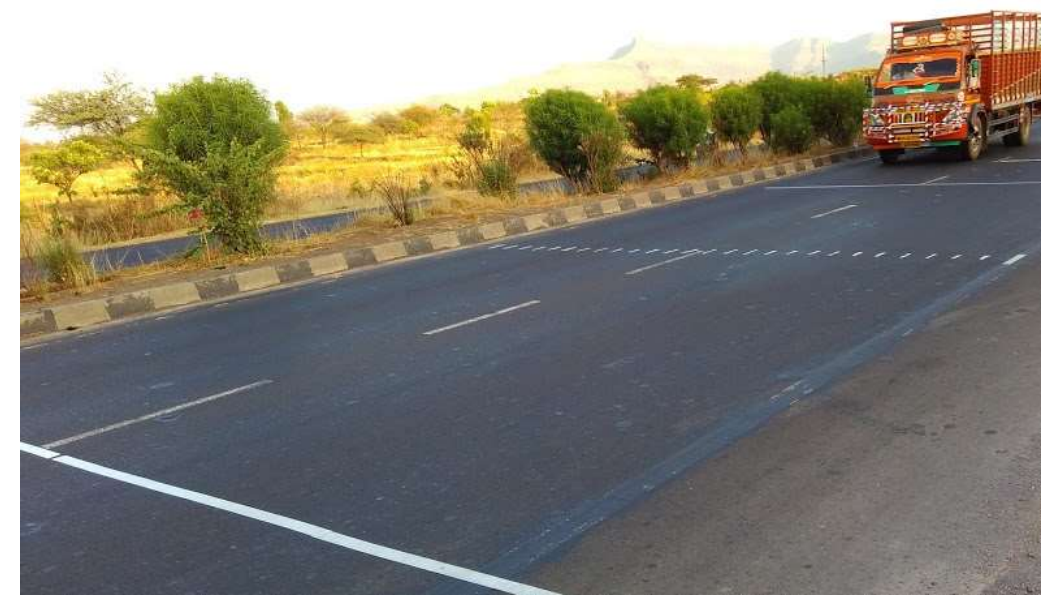

Figure 4: Typical image of the pavement marking set-up

The speed, lateral position and interaction type data were extracted manually using the video editing software in the laboratory. At each study site, for each type of interaction, at least thirty sample data (i.e., speed and lateral position data) were extracted. To evaluate the type of interaction, the video recordings of passenger cars were tracked frame by frame at all the three locations (i.e., $\mathrm{PC}_{50}, \mathrm{PC}$, and $\mathrm{CC}$ ) of a site. Speed and lateral positions were estimated at the curve center.

Normality of these data was successfully verified using the Kolmogorov-Smirnov test $(\mathrm{P}$-value $>0.05)$. Using these data a t-test was performed to compare NI-NI-NI case with I-NI-NI, I-I-NI, and NI-I-NI at 95\% confidence interval. The estimated significance (pvalue) was $0.04,0.00$, and 0.01 , respectively. It confirmed a statistically significant difference and warranted further investigation for all the four sites. Descriptive statistics of the extracted speed and lateral position data for all the four sites are presented in Table 2 and Table 3, respectively. Further analysis in the subsequent section elaborates the speed and lateral position behavior for all the four cases of inter-vehicle interaction. 
Table 2: Descriptive statistics of the extracted speed data ( $\mathrm{kmph})$

\begin{tabular}{|c|c|c|c|c|c|c|c|}
\hline Site no. & Radius (m) & Station & Statistics & NI-NI-NI & NI-I-NI & I-I-NI & I-NI-NI \\
\hline \multirow{6}{*}{1} & \multirow{6}{*}{90} & $\mathrm{PC}_{50}$ & \multirow{3}{*}{$\mu$} & 78 & 77 & 63 & 74 \\
\hline & & $\mathrm{PC}$ & & 78 & 73 & 68 & 77 \\
\hline & & $\mathrm{CC}$ & & 77 & 77 & 72 & 78 \\
\hline & & $\mathrm{PC}_{50}$ & \multirow{3}{*}{$\sigma$} & 10 & 10 & 12 & 9 \\
\hline & & $\mathrm{PC}$ & & 11 & 12 & 11 & 9 \\
\hline & & $\mathrm{CC}$ & & 11 & 11 & 9 & 9 \\
\hline \multirow{6}{*}{2} & \multirow{6}{*}{165} & $\mathrm{PC}_{50}$ & \multirow{3}{*}{$\mu$} & 73 & 72 & 69 & 75 \\
\hline & & $\mathrm{PC}$ & & 73 & 71 & 68 & 76 \\
\hline & & $\mathrm{CC}$ & & 75 & 75 & 74 & 77 \\
\hline & & $\mathrm{PC}_{50}$ & \multirow{3}{*}{$\sigma$} & 10 & 10 & 11 & 9 \\
\hline & & $\mathrm{PC}$ & & 10 & 10 & 12 & 9 \\
\hline & & $\mathrm{CC}$ & & 10 & 8 & 12 & 11 \\
\hline \multirow{6}{*}{3} & \multirow{6}{*}{280} & $\mathrm{PC}_{50}$ & \multirow{3}{*}{$\mu$} & 88 & 85 & 86 & 90 \\
\hline & & $\mathrm{PC}$ & & 91 & 84 & 87 & 94 \\
\hline & & $\mathrm{CC}$ & & 90 & 87 & 92 & 95 \\
\hline & & $\mathrm{PC}_{50}$ & \multirow{3}{*}{$\sigma$} & 13 & 18 & 15 & 11 \\
\hline & & $\mathrm{PC}$ & & 13 & 16 & 15 & 13 \\
\hline & & $\mathrm{CC}$ & & 12 & 17 & 15 & 14 \\
\hline \multirow{6}{*}{4} & \multirow{6}{*}{360} & $\mathrm{PC}_{50}$ & \multirow{3}{*}{$\mu$} & 82 & 83 & 80 & 82 \\
\hline & & $\mathrm{PC}$ & & 81 & 79 & 79 & 85 \\
\hline & & $\mathrm{CC}$ & & 84 & 85 & 83 & 87 \\
\hline & & $\mathrm{PC}_{50}$ & \multirow{3}{*}{$\sigma$} & 13 & 11 & 12 & 10 \\
\hline & & $\mathrm{PC}$ & & 13 & 11 & 12 & 11 \\
\hline & & $\mathrm{CC}$ & & 13 & 10 & 12 & 11 \\
\hline
\end{tabular}

Where; $\mu=$ Mean, $\sigma=$ Standard deviation

Table 3: Descriptive statistics of the extracted lateral position data $(\mathrm{cm})$ at curve center

\begin{tabular}{|c|c|c|c|c|c|c|}
\hline Site no. & Radius (m) & Statistics & NI-NI-NI & NI-I-NI & I-I-NI & I-NI-NI \\
\hline \multirow{2}{*}{1} & \multirow{2}{*}{90} & $\mu$ & 406 & 399 & 438 & 432 \\
\hline & & $\sigma$ & 94 & 114 & 74 & 52 \\
\hline \multirow{2}{*}{2} & \multirow{2}{*}{165} & $\mu$ & 405 & 353 & 429 & 436 \\
\hline & & $\sigma$ & 149 & 134 & 118 & 123 \\
\hline \multirow{2}{*}{3} & \multirow{2}{*}{280} & $\mu$ & 321 & 347 & 341 & 383 \\
\hline & & $\sigma$ & 121 & 81 & 98 & 75 \\
\hline \multirow{2}{*}{4} & \multirow{2}{*}{360} & $\mu$ & 298 & 285 & 314 & 323 \\
\hline & & $\sigma$ & 123 & 172 & 138 & 129 \\
\hline
\end{tabular}

Where; $\mu=$ Mean, $\sigma=$ Standard deviation

\section{Analysis and Results}

The speed and lateral position data were analyzed for the possible influence of vehicle interaction on $5 \mathrm{sec}$ threshold headway based free-flow speed at the curve center. The number of interactions per hour for each case is presented in Table 4 . The $85^{\text {th }}$ percentile $\left(V_{85}\right)$ of the speed data at three locations were estimated separately for the four cases.

Table 4: Casewise number of interactions per hour of video

\begin{tabular}{ccccc}
\hline Interaction cases & Site $1, \mathrm{R}=90(\mathrm{~m})$ & Site $2, \mathrm{R}=165(\mathrm{~m})$ & $\mathrm{Site} 3, \mathrm{R}=280(\mathrm{~m})$ & Site $4, \mathrm{R}=360(\mathrm{~m})$ \\
\hline NI-NI-NI & 22 & 31 & 26 & 39 \\
NI-I-NI & 14 & 13 & 18 & 23 \\
I-I-NI & 18 & 17 & 21 & 32 \\
I-NI-NI & 29 & 28 & 21 & 34 \\
\hline
\end{tabular}




\subsection{Effect on speed}

The $85^{\text {th }}$ percentile speed $\left(\mathrm{V}_{85}\right)$ profiles for the inter-vehicle interaction cases were plotted along the three locations (i.e., $\mathrm{PC}_{50}, \mathrm{PC}$, and $\mathrm{CC}$ ) of the four horizontal curves (see Figure 5 ). These plots represent the effects of inter-vehicle interaction on speed choice profile. It is clear that the drivers maintained the preferred speed at all the three locations along a curve when not influenced at all the three locations (i.e., for NI-NI-NI case). This trend is consistent at all the sites and can be referred as the preferred speed of the sites. For all the sites, the speed drops at the $2^{\text {nd }}$ location (i.e., PC) for the NI-I-NI case. It confirms the influence of inter-vehicle interaction at the $2^{\text {nd }}$ location. However, it seems, immediately after this effect, drivers accelerated and attained the preferred speed at the curve center (i.e., CC) of all the three sites except at site 4 . In case of site 4, speed was approximately $2 \mathrm{kmph}$ lower than the preferred speed at the $\mathrm{CC}$, which is not significant and can be considered as same. Similarly, when there was any inter-vehicle interaction at $1^{\text {st }}$ location $\left(\mathrm{PC}_{50}\right)$, i.e., the I-NI-NI case, the speed choice met the preferred speed at the CC for $90 \mathrm{~m}$ radius curve. Whereas, for a higher radius, it immediately attained the preferred speed at $2^{\text {nd }}$ location (PC). This difference may be attributed to the defensive driving nature for the sharper curve. Otherwise, if there was no influence, drivers might have accelerated abruptly to reach their preferred speed at the $2^{\text {nd }}$ location (PC).
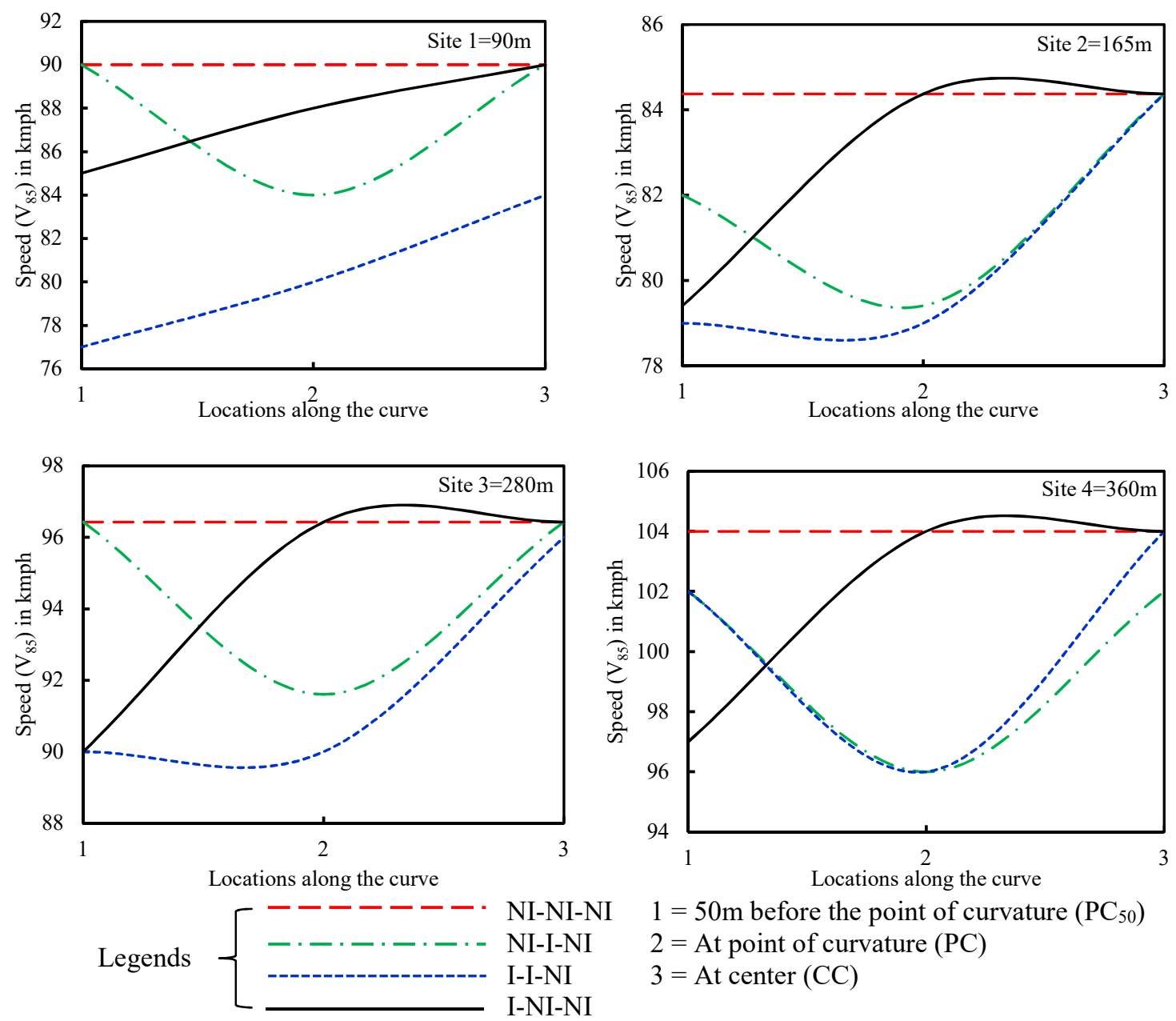

Figure 5: Speed profile along the horizontal curve 
Similar observation for the I-I-NI case supports this finding. It was noted that for the I-I-NI case in $90 \mathrm{~m}$ curve, the drivers were unable to reach the preferred speed at the CC. Whereas, for the other higher radius curves, they achieve it. The dissimilar trend for $90 \mathrm{~m}$ curve may be attributed to the speed drop for defensive driving behavior on sharper curve. Also, it can be observed that for this case at site 2 and site 3 (radius $165 \mathrm{~m}$ and $280 \mathrm{~m}$ ) drivers maintained a speed at $1^{\text {st }}\left(\mathrm{PC}_{50}\right)$ and $2^{\text {nd }}$ location $(\mathrm{PC})$ and then accelerated to attain the preferred speed at the CC. This was the anticipated trend for this case. In spite of the influence of inter-vehicle interactions, the observed higher speed choice at $\mathrm{PC}_{50}$ of site 4 $(\mathrm{R}=360 \mathrm{~m})$ might attribute to the effects of longer preceding tangent length.

\subsection{Effect on lateral position (LP)}

The lateral position at the curve center (CC) was considered as a complementary indicator of the influence of inter-vehicle interaction. Figures 6 to 9 presents the frequency distribution of lateral position for all the four conditions at sites 1, 2, 3 and 4, respectively. The abscissa designates the lateral position of vehicles from the outside edge line marking of the carriageway in a curve. Whereas, the ordinate represents the frequency of vehicles observed at certain lateral position with an accuracy of $25 \mathrm{~cm}$.
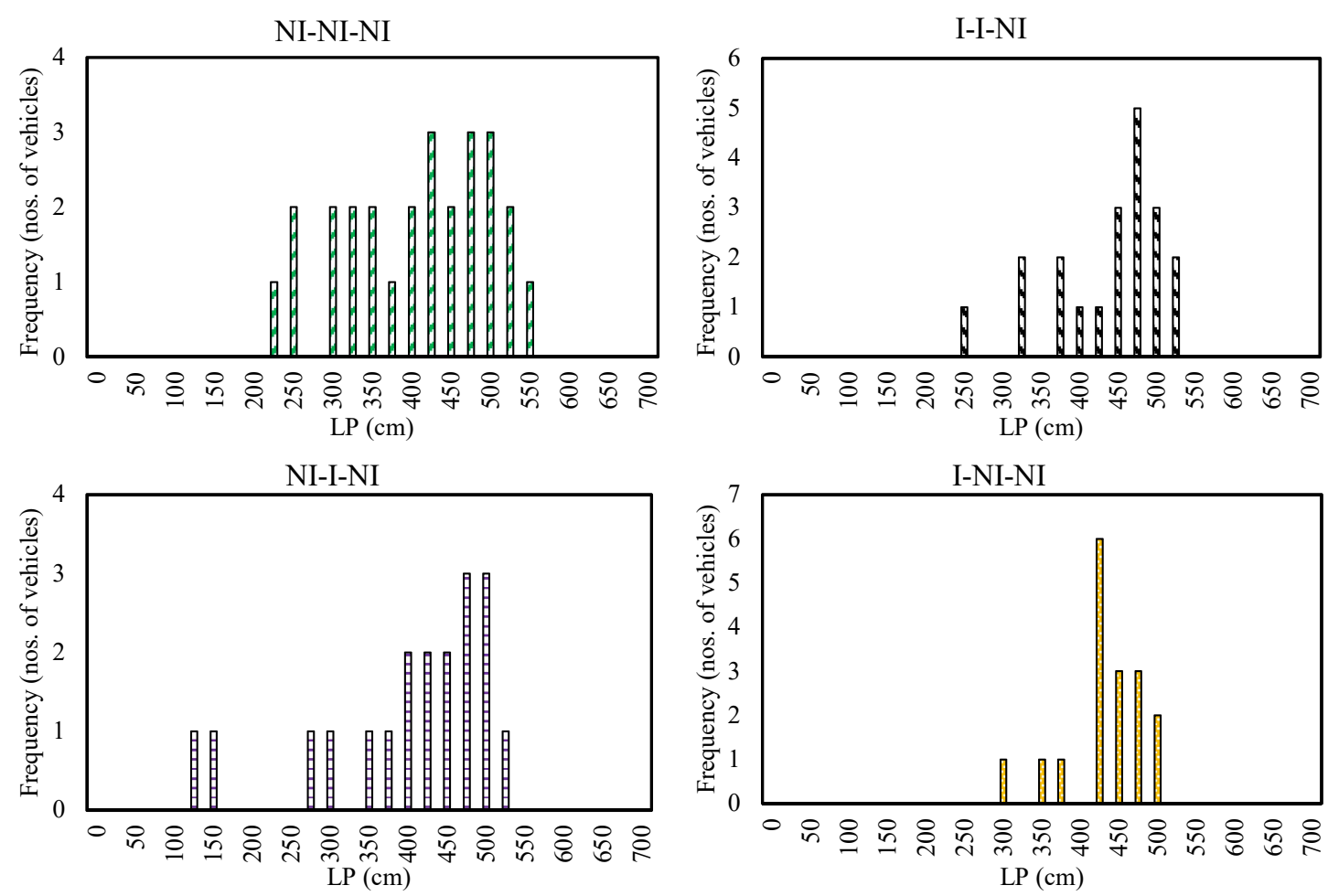

Figure 6: Lateral position for site $1(\mathrm{R}=90 \mathrm{~m})$ 

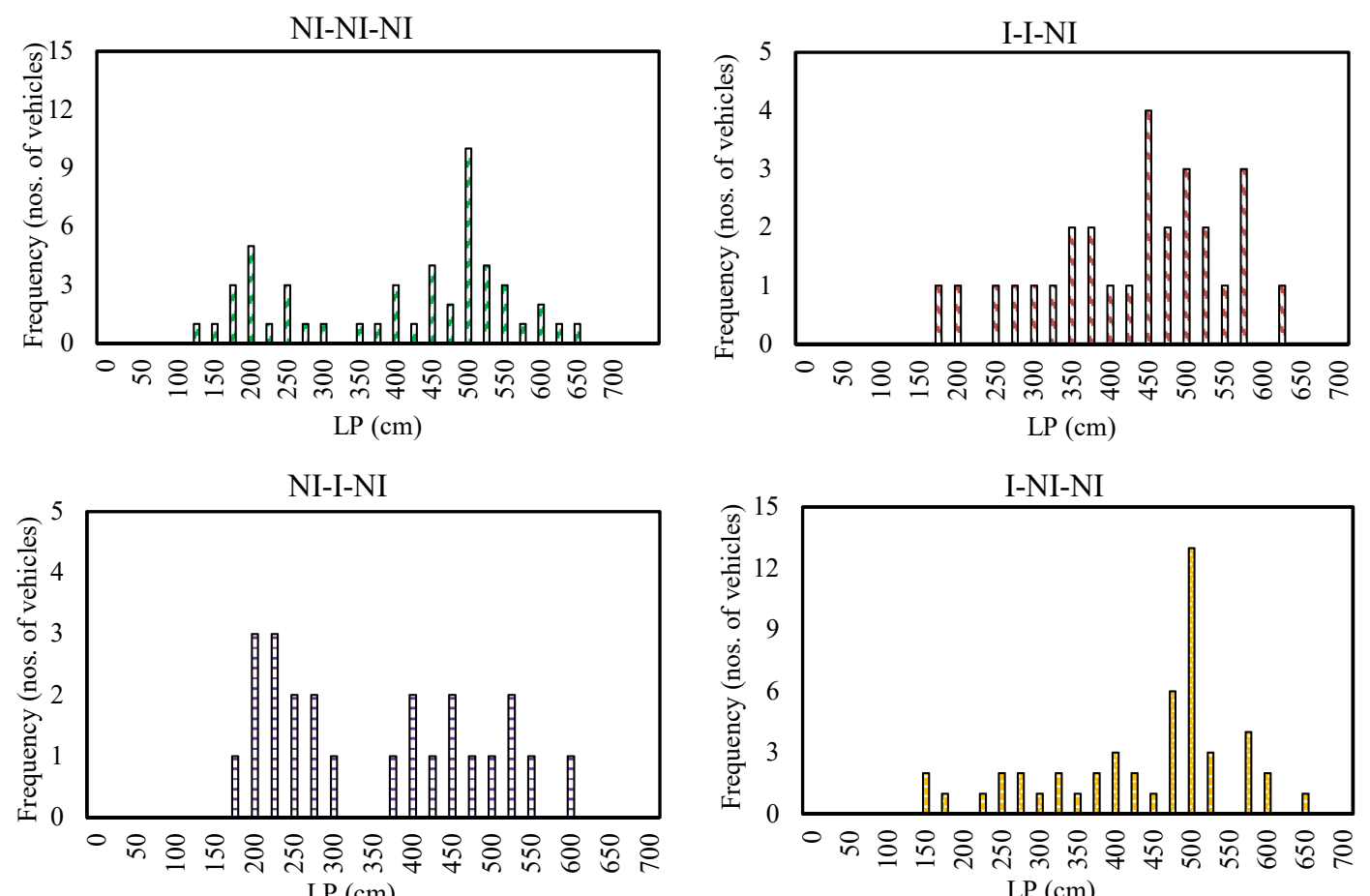

Figure 7: Lateral position for site $2(\mathrm{R}=165 \mathrm{~m})$
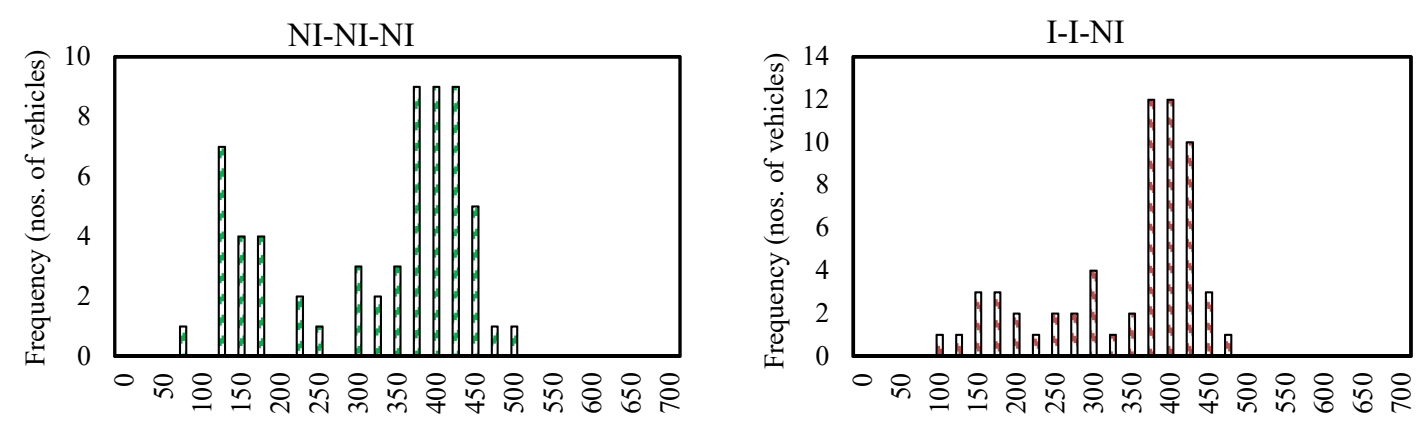

LP $(\mathrm{cm})$

LP $(\mathrm{cm})$
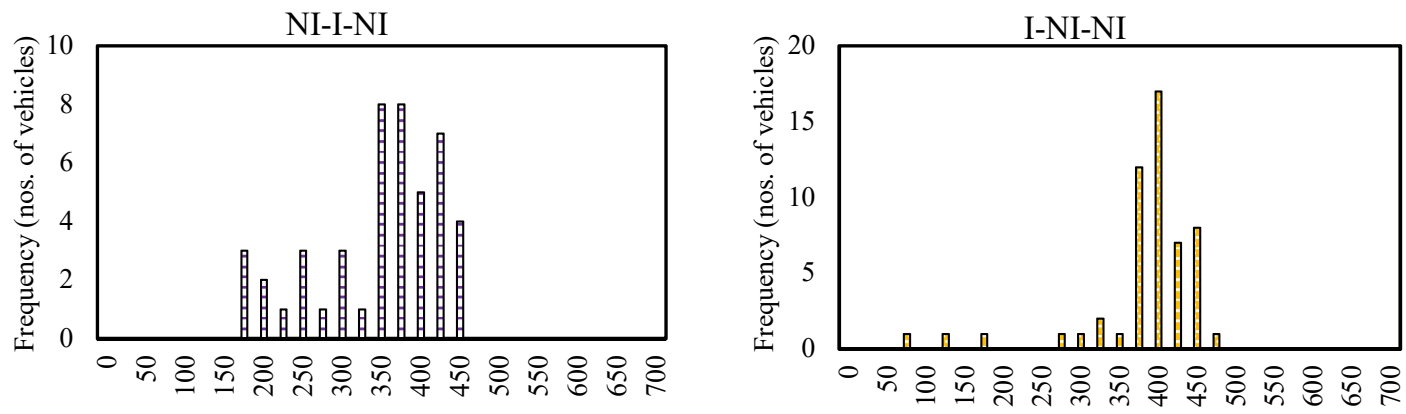

LP (cm)

LP $(\mathrm{cm})$

Figure 8: Lateral position for site $3(\mathrm{R}=280 \mathrm{~m})$ 

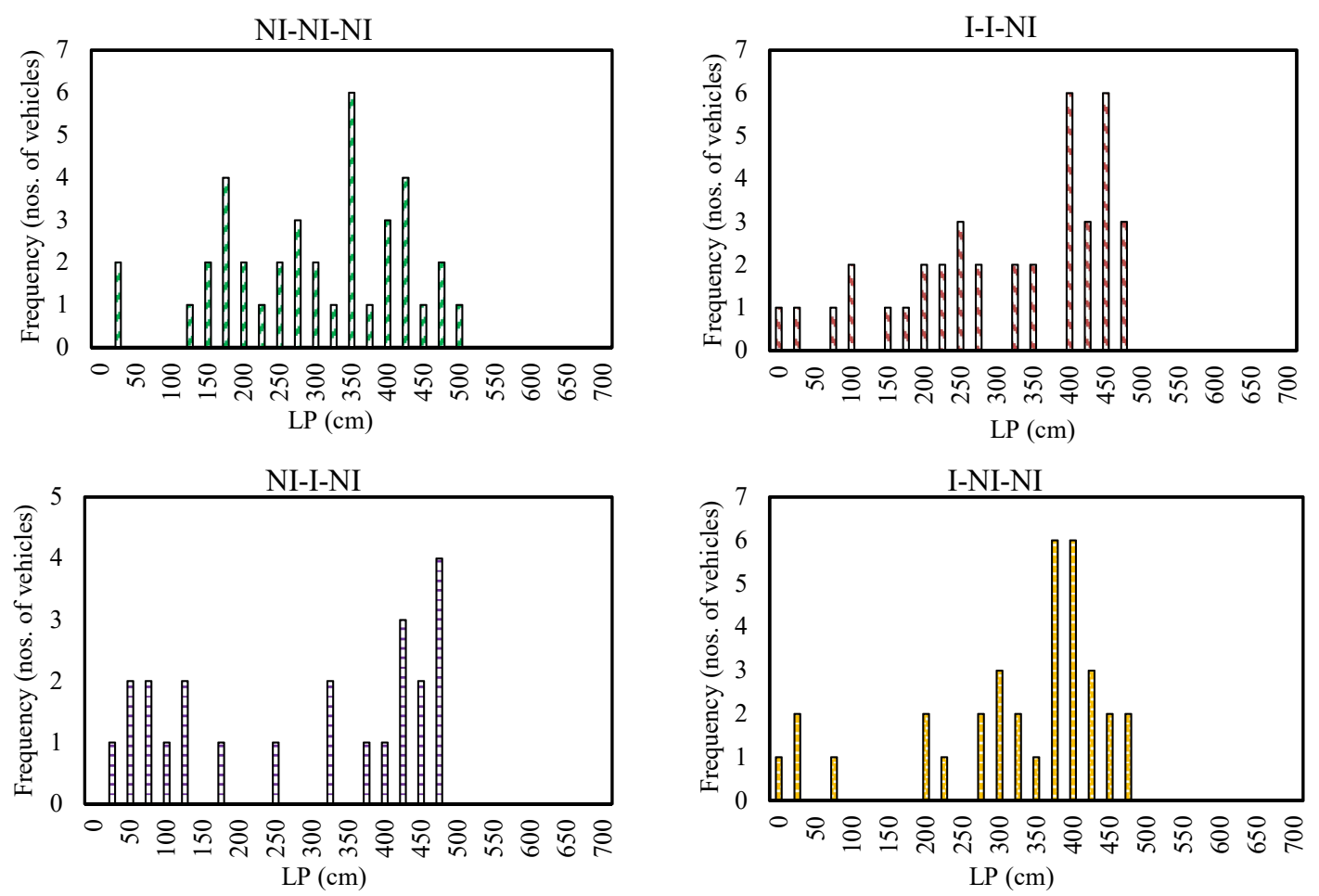

Figure 9: Lateral position for site $4(\mathrm{R}=360 \mathrm{~m})$

For $90 \mathrm{~m}$ radius curve, the lateral position was almost concentrated between $200 \mathrm{~cm}$ and $550 \mathrm{~cm}$ and has a peak between $400 \mathrm{~cm}$ and $500 \mathrm{~cm}$ for all the conditions. This may be attributed to the sharper curve radius. In other words, vehicles chose to move towards the median side lane for sharper curve radius. For the NI-NI-NI case, two clear peaks were observed at sites 2, 3 and 4. Also, the vehicles used a wide carriageway compared to the other conditions. At all the sites, other than the NI-NI-NI case, all conditions had one peak. Further, at sites 2 and 4, NI-I-NI case had two peaks, but at those sites, the vehicles were widely distributed for the NI-NI-NI case. The lane wise percentage share of vehicles lateral position is presented in Table 5. It was observed that the lateral position shifted towards the inside lane when the vehicle was affected prior to the center. A higher percentage of inside lane and high negative skewness in case of I-I-NI and I-NI-NI confirmed this fact. In case of NI-NI-NI and NI-I-NI, the comparatively high usage of outer lane (based on the percentage share of lateral position in each lane), less negative skewness and observations from Figures 6 to 9 indicated drivers were likely to use both the lanes. However, drivers were likely to choose inside lane for $90 \mathrm{~m}$ radius curve. This may be due to the effect of curvature.

Table 5: Lane-wise percentage share of the vehicles

\begin{tabular}{|c|c|c|c|c|c|c|c|c|c|c|c|c|c|}
\hline \multirow[b]{2}{*}{$\begin{array}{l}\text { Site } \\
\text { No. }\end{array}$} & \multirow[b]{2}{*}{$\mathrm{R}$} & \multicolumn{3}{|c|}{ NI-NI-NI } & \multicolumn{3}{|c|}{ I-I-NI } & \multicolumn{3}{|c|}{ NI-I-NI } & \multicolumn{3}{|c|}{ I-NI-NI } \\
\hline & & $\begin{array}{c}\text { OL } \\
\%\end{array}$ & $\begin{array}{l}\text { IL } \\
\% \\
\end{array}$ & $\gamma$ & $\begin{array}{c}\text { OL } \\
\%\end{array}$ & $\begin{array}{l}\text { IL } \\
\% \\
\end{array}$ & $\gamma$ & $\begin{array}{c}\text { OL } \\
\%\end{array}$ & $\begin{array}{l}\text { IL } \\
\% \\
\end{array}$ & $\gamma$ & $\begin{array}{c}\text { OL } \\
\% \\
\end{array}$ & $\begin{array}{l}\text { IL } \\
\% \\
\end{array}$ & $\gamma$ \\
\hline 1 & 90 & 12 & 88 & -0.38 & 5 & 95 & -1.10 & 16 & 84 & -1.33 & 0 & 100 & -1.10 \\
\hline 2 & 165 & 28 & 72 & -0.43 & 11 & 89 & -0.49 & 38 & 62 & 0.28 & 12 & 88 & -0.79 \\
\hline 3 & 280 & 31 & 69 & -0.64 & 22 & 78 & -1.01 & 20 & 80 & -0.82 & 6 & 94 & -2.54 \\
\hline 4 & 360 & 37 & 63 & -0.41 & 36 & 64 & -1.32 & 44 & 56 & 0.48 & 21 & 79 & 0.70 \\
\hline
\end{tabular}




\section{Discussion}

The speed and lateral position data presented in Table 2 and Table 3 indicate less variation in the mean $(\mu)$ and standard deviation $(\sigma)$ of speed in case of NI-NI-NI. In other words, the inter-vehicle interactions induce variations in speed and lateral positions. Further, the speed profile plots in Figure 5 confirm the influence of inter-vehicle interaction prior to a curve on the speed and lane position at the curve center. Though the mean speed at the $\mathrm{CC}$ did not vary with the radius (see Table 2 ), the $85^{\text {th }}$ percentile speed or operating speed increased with radius (see Figure 5). It indicates the radius influences the operating speed of a horizontal curve in the four-lane divided highways (Sil et al. 2019a). However, the low operating speed of Site 2 (i.e., Radius $=165 \mathrm{~m}$ ) can be attributed to the influence of other geometric features (such as shorter preceding tangent length compare to other sites). As observed in Figure 5, for all the four cases, the operating speed was almost similar at $\mathrm{CC}$ but was different at other locations. Again, at each site, the operating speeds at all the three locations remained constant for vehicles with no inter-vehicle interaction (i.e., NINI-NI case). It validates the assumption of constant speed along the entire curve for operating speed modeling. These findings indicate that the vehicular interactions prior to a CC (i.e., other than NI-NI-NI cases) impose additional workload on drivers due to speed adjustments. Though the operating speed of such vehicles at $\mathrm{CC}$ was not different from the operating speed of vehicles that did not have any inter-vehicle interactions, the drivers might experience additional workload while negotiating the curve after having intervehicle interactions prior to the curve center. It can be safely assumed that their driving behavior is not solely influenced by highway geometry. Hence, these vehicles are not recommended for studies that evaluate the influence of highway geometry. The NI-NINI case is the most suitable for such studies.

The results also indicated that for the sites considered, vehicles generally used the inner lane more than the outer lane. The percentage of vehicles using the inner lane increased when inter-vehicle interaction happened at $\mathrm{PC}_{50}$. But, inter-vehicle interaction only at PC helped to balance the lane usage to some extent. If these findings persist in other locations of a highway, the lane utilization factors considered in highway capacity estimation may need to be reviewed. More such studies are warranted for heavy commercial vehicles to review the lane distribution factors considered in pavement design.

\section{Conclusion}

In this research, vehicle speed and lateral position at the curve center were studied for the possible influence of inter-vehicle interactions at locations prior to the curve center. The speed and lateral position data on four different horizontal curves along four-lane divided highway were collected and analyzed for possible inter-vehicle interactions. The speed data were used to develop the 85th percentile speed profiles along the horizontal curves and the lateral position data to plot the frequency distribution at curve center. It was observed that the vehicle maintained an uniform speed profile when not influenced by inter-vehicle interaction till the curve center (i.e., NI-NI-NI case). For cases with intervehicle interactions at locations prior to the curve center, there was an additional speed adjustment workload imposed on the drivers. Hence, such vehicles cannot be considered as truly free-flowing and may not be adopted for developing the speed prediction models of horizontal curves. The influenced vehicles were found shifting to the inside lane and making the trajectory relatively flatter. It indicates a defensive driving post inter-vehicle interaction, and needs further research to understand the effect on safety and evaluation 
of horizontal curves. The comparison of the speed profile and lateral position for the overall uninfluenced case (NI-NI-NI) and the other three influenced cases indicates a clear difference. Therefore, the specific contributions of the study can be summarized as follows:

(i) Established the requirements to investigate the inter-vehicle interactions prior to an observation station.

(ii) Recommended the overall uninfluenced case (NI-NI-NI condition) for free-flow speed data collection at the curve center of four-lane divided highways. It confirmed the sole influence of the curve geometry on subject vehicle speed.

(iii) Proposed a truly free-flow evaluation methodology for operating speed estimation at the curve center of four-lane divided highways.

The effect of inter-vehicle interaction was considered for passenger cars only. Similar studies on other vehicle categories can be conducted for holistic knowledge of this effect. Moreover, other geometric elements like tangent, vertical curves and, combination of horizontal and verticals curves can be studied for the effect of inter-vehicle interactions. Additionally, similar study on other roadway facilities (e.g., two-lane and six-lane highways) can help to comprehensively evaluate the free-flow condition for the singlevehicle safety assessment of geometric design.

\section{References}

AASHTO (2011). "A policy on geometric design of highways and streets." AASHTO, Washington, D. C.

Bassani, M., C. Cirillo, S. Molinari, and J. M. Tremblay. (2016). "Random effect models to predict operating speed distribution on rural two-lane highways." J. Transp. Eng. 142 (6): 04016019. https://doi.org/10.1061/(ASCE)TE.1943-5436.0000844.

Boora, A., Ghosh, I., and Chandra, S. (2016). "Identification of free flow condition on two-lane intercity highways under heterogeneous traffic condition." $27^{\text {th }} A R R B$ Conference, Melbourne, Australia.

Campbell, J.L., Richard, C.M., and Graham, J. (2008). "Human factors guidelines for roadway systems." NCHRP Report 600B, Transportation Research Board, National Research Council, Washington, D. C.

Choudhari, T. and Maji, A. (2018). Assessment of Driver Performance based on Driver Demography and Road Geometry. Transportation Research Board (TRB) 97th Annual Meeting, Washington, D.C., USA.

Choudhari, T. and Maji, A. (2019a). Analysis of Drivers' Speed Behaviour along Horizontal Curves of Two-lane Rural Highways using Driving Simulator. 5th Conference of Transportation Research Group of India (CTRG) 2019, 18-211 December 2019, Bhopal, India.

Choudhari, T. and Maji, A. (2019b). Socio-demographic and Experience Factors Affecting Drivers' Runoff Risk along Horizontal Curves of Two-lane Rural Highway. Journal of Safety Research, 71, 1-11.

Choudhari, T. and Maji, A. (2019c). Effect of Horizontal Curve Geometry on the Maximum Speed Reduction - A Driving Simulator based Study. Transportation in Developing Economies, 5(2), 14.

Choudhari, T., Maji, A. (2017). Miscellaneous Study on Speed Reduction along Horizontal Alignments of Rural Highway: A Driving Simulator based Approach for 
Developing Countries. Transportation Research Board (TRB) 96th Annual Meeting, Washington, D.C., USA.

Dey, P.P., Chandra, S., and Gangopadhaya, S., (2006). "Speed distribution curves under mixed traffic conditions." Journal of transportation engineering, 132(6), 475-481.

Fitzpatrick, K. and Collins, J. M. (2000). "Speed-profile model for two-lane rural highways." Transportation Research Record, 1737, Transportation Research Board, Washington, D. C., United States, 42-49.

Fitzpatrick, K., Harwood, D. W., Omer, T., Collins, J. M., Paul, G., Bauer, K. M., Kelly, D. P., Rodger, K., Douglas, H. W., Ingrid, A., Krammes, R. A., and Brian, P. (2000) "Alternative design consistency rating methods for two-lane rural highways." Report No. FHWA-RD-99-172, FHWA, U.S. Department of Transportation, Washington, D. C., United States.

Glennon, J. C., Neuman, T. R., and Leisch, J. E. (1983). "Safety and operational considerations for design of rural curves." Report No. FHWA/RD-86/035, FHWA, U.S. Department of Transportation, Washington, D. C., United States.

Gong, H., and Stamatiadis, N. (2008). "Operating speed prediction models for horizontal curves on rural four-lane highways." Transportation Research Record, 2075, Journal of the Transportation Research Board, Washington, D. C., United States, 1-7.

Hashim, I. H., Abdel-Wahed, T. A., and Moustafa, Y. (2016). "Toward an operating speed profile model for rural two-lane roads in Egypt." Journal of Traffic and Transportation Engineering (English edition), 3(1), 82-88.

Hassan, Y., M. Sarhan, M. Dimaiuta, and R. Porter. (2011). Modeling operating speed: Synthesis report. Chapter 7: Conclusions and recommendations. Transportation Research E-Circular, Issue Number: E-C151. Washington, DC: Transportation Research Board.

Jacob, A., and Anjaneyulu, M. V. L. R. (2012). "Operating speed of different classes of vehicles at horizontal curves on two-lane rural highways." Journal of Transportation Engineering, 139(3), 287-294.

Lamm, R., Choueiri, E.M., and Mailaender, T. (1990). "Comparison of operating speeds on dry and wet pavements of two-lane rural highways." Transportation Research Record, 1280, Journal of the Transportation Research Board, Washington, D. C., United States, 199-207.

Lamm, R., Guenther, A. K., and Choueiri, E. M. (1995). "'Safety module for highway geometric design." Transportation Research Record, 1512, Journal of the Transportation Research Board, Washington, D. C., United States, 7-15.

Maji, A., and Tyagi, A. (2018). "Speed prediction models for car and SUV at locations along four-lane median divided horizontal curves." Journal of Modern Transportation, 1-7, https://doi.org/10.1007/s40534-018-0162-1

Maji, A., Sil, G., and Tyagi, A. (2018). "85th and 98th percentile speed prediction models of car, light, and heavy commercial vehicles for four-lane divided rural highways." Journal of Transportation Engineering, Part A: Systems, 144(5), 04018009.

Misaghi, P., and Hassan, Y. (2005). "Modelling operating speed and speed differential on two-lane rural roads." Journal of Transportation Engineering, 131(6), 408-418.

Mohapatra, S. S., and Dey, P. P. (2015). "Lateral placement of U-turns at median openings on six-lane divided urban roads." Transportation Letters, 7(5), 252-263. 
Nama, S., Sil, G., Maurya, A. K., and Maji, A. (2016). "Speed prediction models of fourlane horizontal curves for Indian driving behavior." Transportation Planning and Implementation Methodologies for Developing Countries, Mumbai, India.

Nama, S., Sil, G., Maurya, A.K. and Maji, A. (2018). Acceleration and Deceleration Behavior in Departing and Approaching Sections of Curve Using Naturalistic Driving Data. Recent Advances in Traffic Engineering (RATE) 2018, 11-12 August 2018, Sardar Vallabhbhai National Institute of Technology, Surat, India.

Ottesen, J. L., and Krammes, R. A. (2000). "Speed-profile model for a design-consistency evaluation procedure in the United States." Transportation Research Record, 1701, Transportation Research Board, Washington, D. C., United States, 76-85.

Rawson, C. T. (2015). "Procedures for establishing speed zones." Manual Notice 20151, Texas Department of Transportation.

Sil, G., and Maji, A. (2017a). "Video based data collection process for geometric design consistency evaluation of four-lane median divided horizontal curves." Transportation Research Procedia, 27, 672-679.

Sil, G., and A. Maji. (2017b). "Development of speed prediction model for curve in mixed traffic conditions." International Conference on Advances in Highway Engineering and Transportation Systems (ICAHETS-2017), Negombo, Sri Lanka.

Sil, G., S. Nama, A. Maji, and A.K. Maurya. (2018a). "The 85th percentile speed prediction model for four-lane divided highways in ideal free flow condition." Extended abstract presented at the 97th Annual Meeting of the Transportation Research Board (No. 18-02808), Transportation Research Board, Washington, D. C., United States.

Sil, G.; Mohapatra, S.S., Dey, P.P \& Chandra, S. (2018b). "Merging Process of U-Turns at Uncontrolled Median Openings Under Mixed Traffic Conditions." Transport, Vol. 33, No.2, 370-379. DOI:10.3846/16484142.2016.1247295.

Sil, G., A. Maji, S. Nama, and A.K. Maurya. (2019a). "Operating speed prediction model as a tool for consistency based geometric design of four-lane divided highways." Transport, 34(4), 425-436.

Sil, G., Nama, S., Maji, A., \& Maurya, A. K. (2019b). Effect of horizontal curve geometry on vehicle speed distribution: a four-lane divided highway study. Transportation Letters, 1-10.

Sil, G.; Mohapatra, S.S., Dey, P.P \& Chandra, S. (2019c). "Service Delay and Merging Time Evaluation at Median Openings." European TransportlTrasporti Europei, Vol. March, No. 71, pp. 1-13.

Sil, G., Nama, S., Maji, A., \& Maurya, A. K. (2020a). Modeling 85th Percentile Speed Using Spatially Evaluated Free-Flow Vehicles for Consistency-Based Geometric Design. Journal of Transportation Engineering, Part A: Systems, 146(2), 04019060.

Sil, G., Nama, S., Maji, A. and Maurya, A.K. (2020b). Modeling Operating Speeds for Multilane Divided Highways, in Transportation Research, Tom V. Mathew et al. (Eds), Vol. 45, Springer Singapore.

Taragin, A. (1954). "Driver performance on horizontal curves." 33rd Annual Meeting of the Highway Research Board, National Research Council, Washington, D. C., United States, 446-466.

Tyagi, A. (2016). "Operating and Design Speed Prediction Models for Four-Lane Median Divided Rural Highways." M.Tech. dissertation, Indian Institute of Technology Bombay. 
Zwahlen, H., and Schnell, T. (1999). "Driver-headlamp dimensions, driver characteristics, and vehicle and environmental factors in retroreflective target visibility calculations." Transportation Research Record, 1692, Transportation Research Board, Washington, D. C., United States, 106-118.

\section{Acknowledgments}

Authors would like to thank Ms. Divya Shanu for her support in data extraction. Authors are also thankful to National Highways Authority of India (NHAI) for providing the plan and profile, and Mumbai Nasik Expressway Limited (MNEL) for providing support in field data collection. Further, authors are grateful to the Indian Institute of Technology Bombay for providing financial assistance to conduct the study. 